\title{
Article \\ Development of High Resistance Hot Mix Asphalt with Electric Arc Furnace Slag, Ladle Furnace Slag, and Cellulose Fibers from the Papermaking Industry
}

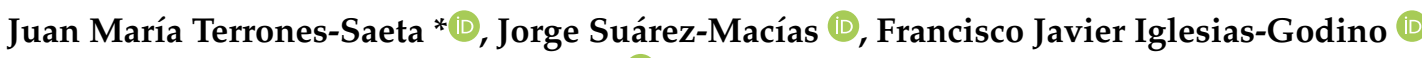 \\ and Francisco Antonio Corpas-Iglesias
}

check for

updates

Citation: Terrones-Saeta, J.M.; Suárez-Macías, J.; Iglesias-Godino,

F.J.; Corpas-Iglesias, F.A. Development of High Resistance Hot Mix Asphalt with Electric Arc Furnace Slag, Ladle Furnace Slag, and Cellulose Fibers from the Papermaking Industry. Appl. Sci. 2021, 11, 399. https://doi.org/ 10.3390/app11010399

Received: 9 December 2020 Accepted: 30 December 2020 Published: 4 January 2021

Publisher's Note: MDPI stays neutral with regard to jurisdictional clai$\mathrm{ms}$ in published maps and institutional affiliations.

Copyright: (C) 2021 by the authors. Licensee MDPI, Basel, Switzerland. This article is an open access article distributed under the terms and conditions of the Creative Commons Attribution (CC BY) license (https:// creativecommons.org/licenses/by/ $4.0 /)$.
Department of Chemical, Environmental, and Materials Engineering, Higher Polytechnic School of Linares, University of Jaen, Scientific and Technological Campus of Linares, 23700 Linares (Jaén), Spain; jsuarez@ujaen.es (J.S.-M.); figodino@ujaen.es (F.J.I.-G.); facorpas@ujaen.es (F.A.C.-I.)

* Correspondence: terrones@ujaen.es

Abstract: Roads are currently essential links of communication and economic development. However, these roads are progressively requiring higher quality materials, implying a greater impact on the environment, in order to withstand the high levels of heavy vehicle traffic. Therefore, this research proposes the use of industrial by-products to create bituminous mixtures which are more resistant and durable than traditional ones. The industrial by-products used, are electric arc furnace slag, ladle furnace slag, and cellulose fibers from the papermaking industry. These by-products were physically and chemically characterized to be used to conform with bituminous mixtures. At the same time, bituminous mixtures were conformed with conventional materials, thus being able to compare the physical and mechanical properties of the conformed mixtures through different tests. The results showed how the use of cellulose fibers made it possible to absorb a greater percentage of bitumen, as well as the use of electric arc furnace slag and ladle furnace slag created mixtures, with greater Marshall stability. Therefore, sustainable, durable, resistant, and high waste mixtures were developed in this investigation.

Keywords: bituminous mixtures; discontinuous grading; pavement; electric arc furnace slag; ladle furnace slag; steel; cellulose fibers; Marshall stability; sustainability; circular economy

\section{Introduction}

At the present time, roads are progressively being loaded more heavily due to the increase in heavy vehicle traffic, as these infrastructures are the essential communication links for the transport of goods over medium and short distances [1]. Therefore, roads should be built with higher quality materials, with more optimized production procedures, with a longer working life, and with better mechanical behavior.

In turn, road construction is one of the most polluting activities in existence today [2]. The environmental impact caused by these infrastructures is mainly due to the modification of the landscape, the extraction of enormous quantities of raw materials, the emissions produced during their working lives by continuous vehicle traffic, as well as the waste which is obtained after the ageing of the materials which make up the road [3,4]. It is therefore logical to think that new pavements which are more sustainable with the environment should be developed, but which at the same time do not involve a sacrifice of mechanical characteristics [5].

Different techniques are currently available to minimize greenhouse gas emissions in the bituminous mixes for roads [6]. It should be noted that bituminous mixtures are the fundamental material of the pavement, as they are the most economically expensive element and use higher quality materials. In order to manufacture these mixes in a more sustainable way, different types of binders and additives have been used to reduce the 
conforming temperature [7], since usually for the manufacture of hot mix asphalt, the aggregates and the binder must be heated to temperatures of around $180^{\circ} \mathrm{C}$, with the consequent consumption of fossil fuels and the relevant $\mathrm{CO}_{2}$ emissions [8]. These techniques with lower conforming temperatures have been successfully carried out; however, in most cases they involve sacrificing mechanical properties. Therefore, the higher requirement for quality mixtures in most cases is incompatible with this technique [9].

On the other side, the waste that has been used for the conforming of the bituminous mixtures. This line has different advantages over others, on the one side, by eliminating the deposition of industrial sub-products in landfills [10]; on the other front, the use of waste in the bituminous mixtures avoids the extraction of new raw materials [11], with the consequent reduction of environmental impact; and finally, by providing a new life for the material $[12,13]$. In addition, the waste can provide the final bituminous mixture with interesting properties for its use, not involving a sacrifice of mechanical characteristics but an increase in its capacity and versatility [14]. There are many investigations carried out in which waste is incorporated for the manufacture of bituminous mixtures; for example, biomass ash [15], ceramic dust [16], construction and demolition waste [17], reclaimed asphalt pavement [18,19], recycled glass [20], recycled plastics [21], etc., in most cases acceptable results were obtained.

In this investigation, based on the above, the wish is to obtain a high-quality bituminous mix to withstand the loads of vehicles on high traffic roads. To do this, waste will be used as raw materials, maximising their characteristics [22] and obtaining greater resistance than that provided by conventional aggregates. The waste used is ladle furnace slag and electric arc furnace slag.

The slag mentioned comes from the metallurgical industry producing steel from scrap [23]. Electric arc furnace slag is derived from the first stage of the production process called the melting stage. These slags have a resistance, particle shape and size very suitable for use as a coarse and fine aggregate in bituminous mixtures. On the other hand, ladle furnace slag derives from the second stage of the steel production process, the refining stage. These slags have a small particle size, making them ideal for use as filler in bituminous mixtures.

There are various investigations in which electric arc furnace slag has been used as a partial substitute for aggregate in hot mix asphalt [24], warm mix asphalt [25], even bituminous mixes with bitumen emulsion [26]. In all these investigations, it was possible to corroborate the excellent mechanical properties of electric arc furnace slag [27], as well as the durability characteristics which they give to the bituminous mix conformed [28]. In turn, the ladle furnace slag has been used in a smaller number of studies, mainly as a partial substitute for cement in concrete [29-31] or in soil stabilization [32]. In these researches, the cementitious properties of the ladle furnace slag could be corroborated $[33,34]$.

Therefore, in this research, both wastes will be used for the conformation of hot mix asphalt of discontinuous grading, as a total substitute of the conventional aggregate, the extraction of aggregates therefore not being necessary. The choice of this type of discontinuous grading bituminous mix is based on different reasons. On the one hand, in this type of mix, the compression loads of the traffic are directly supported by the coarse aggregate through internal friction, so the use of high strength electric arc furnace slag means the optimization of the properties of this waste. On the other hand, in this type of mix a higher void content is obtained, making it possible for rainfall water to be drained off and for the surface roughness of the pavement to be improved. Finally, this type of mix has fewer problems of plastic deformation, since the grading is conformed by a lower percentage of fine aggregate. Nevertheless, in this type of mix, if it does not have an adequate percentage of bitumen, can produce aggregate springing, cracking, and reduction of the working life. Therefore, it is necessary to produce a quality mastic formed with the bitumen and filler capable of resisting traction loads. In this research, the percentage of bitumen is increased to obtain a higher quality mastic and at the same time provide the pavement with the appropriate flexibility for its durability over time. This 
higher percentage of bitumen is obtained by adding cellulose fibers discarded from the papermaking industry.

Cellulose fibers from the papermaking industry are a currently unused waste. These fibers are derived from the process of producing cardboard from recycled paper. The addition of these fibers, conditions the absorption of a higher percentage of bitumen in the bituminous mixture, because if a higher percentage of bitumen is added than the aggregates are capable of absorbing without the addition of these fibers, there will be bleeding of the binder and significant plastic deformations.

In short, in this research, mixtures of high quality and mechanical resistance for high traffic roads are developed, using as coarse and fine aggregate, electric arc furnace slag, ladle furnace slag as filler, and like an additive for the retention of bitumen, cellulose fibers from the papermaking industry. To the evaluation the goodness of the incorporation of this waste, the mixture manufactured was compared with the waste detailed with mixtures of the same category conformed with conventional materials, thus detecting the improvements produced by the use of the waste. At the same time, and with the aim of identifying critical points as well as compatibility between the wastes, a complete physical and chemical characterization of the wastes was carried out.

The results showed that bituminous mixtures conformed to electric arc furnace slag, ladle furnace slag, and cellulose fibers, and possessed greater mechanical resistance and better behavior to plastic deformation. Obtaining, therefore, a quality, resistant, durable, and sustainable bituminous mixture at a lower economic and environmental cost.

\section{Materials and Methods}

This section describes the materials used and the methodology followed for the corroboration of the research hypothesis. The final hypothesis is, as commented on in the methodology, the evaluation of the suitability of electric arc furnace slag, ladle furnace slag, and cellulose fibers to develop discontinuous grading bituminous mixtures high-strength and high-durability.

\subsection{Materials}

The materials used in this research are mainly waste and commercial materials. Waste has a number of advantages over conventional materials, one of which is the low economic and environmental cost. Nevertheless, most of the residues have special physical and chemical characteristics that must be determined to evaluate their aptitude for their use, and in turn, to identify critical points that could damage the material conformed with them.

In addition, the waste must have physical and chemical characteristics that do not change over time, i.e., in different production batches. Otherwise, the properties of the final material would vary, making its use impossible. Electric arc furnace slag, ladle furnace slag, and cellulose fibers have been evaluated over time, and similar characteristics have been obtained, so their use is appropriate. This fact is not always so, the case in other types of waste, such as sewage sludge, the chemical composition varies with the location, the industry, and even with the time of year.

Therefore, this section will mainly describe the origin of the waste and commercial materials, as well as their production process and general characteristics. In the subsequent sections of the methodology, the waste will be tested by evaluating its chemical composition and physical properties.

\subsubsection{Electric Arc Furnace Slag}

Electric arc furnace slag (EAFS) comes from the metallurgical industry in the region of Andalucía, Spain. These industries produce steel mainly from scrap, with electric arc furnace slag being one of the by-products created in greater proportion.

Electric arc furnace slag is produced in the first stage of the process, called the melting stage. This stage is aimed at removing manganese and silicon impurities from the scrap introduced into the electric arc furnace, through the oxidation phase. At the same time, 
there are the phases of dephosphorization and the formation of foaming slag where the impurities are accumulated. This slag is removed at the end of the process and subjected to cooling with watering. It should be noted that electric arc furnace slag is formed in a ratio of approximately 110 to $150 \mathrm{~kg}$ for each ton of steel, so its production can be considered high.

The electric arc furnace slag was taken from the producing company in an unaltered form by dividing the sample into different subgroups depending on the particle size. These subgroups were washed to remove impurities and dried at a temperature of $105 \pm 4{ }^{\circ} \mathrm{C}$ for $24 \mathrm{~h}$ for later use in the methodology. This drying process is carried out in order to remove the humidity from the slag and therefore not to disturb the final results.

\subsubsection{Ladle Furnace Slag}

Ladle furnace slag (LFS) comes, like electric arc furnace slag, from the metallurgical industries in the region of Andalucía, Spain.

This industry of steel production through scrap has a second stage called the refining stage. In this stage, the ladle furnace is fed with the molten liquid from the electric arc furnace and covered with slag. This part of the process is where deoxidation, desulfurization and decarburization of the steel takes place. At the end of the process, the ladle furnace slag is removed.

This slag, unlike the electric arc furnace slag, has a very small particle size, which is why it has been used as a filler for bituminous mixtures in this research. The ladle furnace slag taken from the production industry was dried at a temperature of $105 \pm 4{ }^{\circ} \mathrm{C}$ for $24 \mathrm{~h}$ to remove humidity, and then sieved by the $0.063 \mathrm{~mm}$ sieve. The prepared sample of ladle furnace slag according to this pre-treatment is the one used in the whole methodology.

However, in the results section, the grading curve of the ladle furnace slag is indicated before sieving, i.e., in an unaltered form and with the particle size produced in the metallurgical industry.

\subsubsection{Cellulose Fiber from the Papermaking Industry}

Waste cellulose fibers from the papermaking industry belong to the region of Andalucía, Spain. These fibers, not used at present, play the role of absorbing a greater percentage of bitumen in the bitumen mixture, creating a more flexible and durable mastic over time.

The fibers come from the cardboard production process through recycled paper. To do this, the paper is first milled with water and then subjected to a physical purification process through various sieves. It is then subjected to a subsequent process of cyclonic separation in which light elements are separated from heavy elements. The waste from the latter process is sent to the presses to reduce the water content, forming the discarded fibers used in this research.

The discarded fibers were taken directly from the producing industry, and then subjected to a process for their conditioning and use in bituminous mixtures. This process consisted of washing the fibers with a $30 \%$ sodium hydroxide solution. This washing was carried out for two fundamental reasons: firstly, to paralyze any organic reaction that might occur due to the nature of the fibers; secondly, to remove the natural waxes that remain adhered to the cellulose fibers and impair their correct coating by the bitumen. They were then crushed again and dried at a temperature of $105 \pm 4{ }^{\circ} \mathrm{C}$ for $24 \mathrm{~h}$ to remove humidity. The fibers after this treatment are the ones that have been used in all the methodology and characterization.

\subsubsection{Bitumen}

The bitumen used in all the bituminous mixtures carried out in this investigation is a bitumen without additives called B 60/70. This type of hard penetration bitumen is usual in hot regions such as the study area (Andalucía). The penetration of the bitumen varies 
between the two numbers that define its name and its particular characteristics are detailed in Table 1.

Table 1. Technical specifications of the bitumen used.

\begin{tabular}{ccccc}
\hline Characteristics & Unit & Standard & Min & Max \\
\hline \multicolumn{4}{c}{ Fresh binder } & \\
\hline Penetration $\left(25^{\circ} \mathrm{C}\right)$ & $0.1 \mathrm{~mm}$ & ASTM D5 & 60 & 70 \\
Ductility & $\mathrm{cm}$ & ASTM D113 & 100 & - \\
Solubility & $\%$ & ASTM D2042 & 99.0 & - \\
Flash point & ${ }^{\circ}$ & ASTM D92 & 450 & - \\
\hline Retained penetration & Resistance to Hardening $163{ }^{\circ} \mathrm{C}$ (ASTM D1754) & & \\
Ductility & $\%$ & ASTM D5 & 47 & - \\
\hline
\end{tabular}

\subsubsection{Hornfels Aggregate}

Hornfels aggregate is a high-quality siliceous aggregate. This aggregate has been used as a comparison material with electric arc furnace slag, so that the goodness of the slag's properties as a coarse and fine aggregate could be objectively evaluated in comparison with a quality commercial aggregate.

The aggregate comes directly from hornfels rocks. Hornfels rocks are metamorphic contact rocks with high mechanical resistance and high resistance to freezing and thawing cycles. It is a quality rock capable of providing suitable aggregates for the conformation of bituminous mixtures destined to high traffic roads.

Hornfels aggregate, like electric arc furnace slag, performs the role of a coarse and fine aggregate in detailed bituminous mixtures. For this purpose, the aggregate was subjected to the same process as the electric arc furnace slag; that is, separated into different subgroups according to particle size, washed with water to remove impurities, and dried at a temperature of $105 \pm 4{ }^{\circ} \mathrm{C}$ for $24 \mathrm{~h}$ to remove humidity.

\subsubsection{Calcareous Filler}

The calcareous filler, like the rest of materials and residues, comes from the area of Andalucía, Spain. This filler comes from limestone rocks. Limestone rocks are sedimentary rocks composed mainly of calcium carbonate. These rocks have a lower resistance than siliceous aggregates, however, they are more compatible with bitumen and create a better adhesion. Therefore, and in order to obtain a suitable mastic, this limestone aggregate was used as a filler in some of the bituminous mixtures. In other bituminous mixtures, ladle furnace slag was used in order to compare the goodness of these slags regarding the commercial filler.

For the development of the research, the calcareous filler was subjected to the same process as the ladle furnace slag, dried at a temperature of $105 \pm 4{ }^{\circ} \mathrm{C}$ for $24 \mathrm{~h}$ to remove humidity, and then sieved through the $0.063 \mathrm{~mm}$ sieve.

\subsection{Methodology}

The methodology followed in this research consists of a series of logical and ordered tests to evaluate the suitability of using electric arc furnace slag, ladle furnace slag and cellulose fibers as the main materials for hot mix asphalt with discontinuous grading, high strength, and durability.

To do this, the chemical composition of the waste was first analyzed, as well as its physical properties. That way the suitability of the by-products for use could be objectively evaluated and the existence of critical points to be monitored in subsequent tests could be assessed.

Firstly, different families of bituminous mixtures with the same type of granulometry but with different materials, waste, and commercial materials were executed, evaluating 
the goodness of the use of the waste in comparison with the usual raw materials. The properties that were quantified to determine if these differences were mainly physical and mechanical. These properties were calculated in different sample groups with increasing bitumen percentages for each family.

Finally, and with the data obtained, it was possible to obtain the optimum combination of materials for each family, again making samples of bituminous mixtures for these combinations and corroborating the physical and mechanical properties. In addition, the wheel-tracking test was carried out for these optimal material combinations. This allowed the advantages of using electric arc furnace slag, ladle furnace slag, and cellulose fibers in the detailed bituminous mixtures to be objectively evaluated.

The following sections describe in more detail the tests that are included in each of the phases of the methodology.

\subsubsection{Characterization of Raw Materials}

First of all, the waste was analyzed chemically and physically to determine its properties, as well as those critical points that had to be taken into account to obtain the final material. The waste (electric arc furnace slag, ladle furnace slag, and cellulose fibers) was prepared according to the procedure described in the methodology.

It should be noted that each element performs a different function within the bituminous mixture and has a different nature coming from its production process. Therefore, the tests that were carried out for the waste are individualized. The electric arc furnace slag developed the function of coarse and fine aggregate due to its particle size, the ladle furnace slag performed the function of filler due to its fineness and the cellulose fibers were the additive for the highest bitumen retention.

Based in the comments above, cellulose fibers are the additive that must be distributed homogeneously in the mixture and possess adequate adhesion. Therefore, analysis of the chemical composition is essential to evaluate compatibility with bitumen. The test carried out for this purpose was that of elemental analysis as it is an organic material, detecting the percentages of carbon, nitrogen, hydrogen, and sulfur in the sample. At the same time, the scanning electron microscope test was carried out to observe the fibers at high magnifications and identify their size and distribution.

On the other hand, the ladle furnace slag was subjected to the elemental analysis test, detecting the organic part of the slag as well as the possible carbonation and hydration of the compounds. As the ladle furnace slag is mainly an inorganic material, the X-ray fluorescence test was carried out to identify the chemical elements present in the sample. It should be highlighted, that the identified chemical elements present different properties depending on the chemical compound that has been formed with them; therefore, the X-ray diffraction test was carried out to evaluate the potential chemical compounds present in the ladle furnace slags. The above tests determined the chemical composition of the ladle furnace slag; however, this slag must have certain physical properties for use as a filler in bituminous mixtures. In order to obtain the physical properties of ladle furnace slag and thus evaluate its goodness as a filler in bituminous mixtures, particle density tests were carried out in accordance with the UNE-EN 1097-7 standard, bulk density in kerosene in accordance with the UNE-EN 1097-3 standard and plasticity index in accordance with the UNE 103,103 and UNE 103,104 standards. However, firstly the grading curve of the ladle furnace slag as received from the production industry was analyzed, as detailed in the section on materials. This grading curve showed the high percentage of particles smaller than $0.063 \mathrm{~mm}$, which are used in this research after sieving.

Subsequently, the electric arc furnace slag was subjected to a series of tests to determine its chemical composition. Firstly, the elemental analysis test was carried out to identify the presence of carbon, nitrogen, hydrogen, and sulfur in the sample. These elements must be quantified because they greatly condition the final material properties. At the same time, the X-ray fluorescence test was carried out to quantify the presence of the rest of the chemical elements, identifying those elements that could be harmful to the 
bituminous mix conformed. Next, and as has been commented on in the case of ladle furnace slag, the detection of the compounds in which the chemical elements identified by X-ray fluorescence are combined is essential to objectively determine the behavior of the electric arc furnace slag. Therefore, the X-ray diffraction test performed identifying the main chemical compounds. Once the chemical composition of the electric arc furnace slag had been determined in detail, various physical and mechanical tests were carried out to evaluate the suitability of this waste as a coarse and fine aggregate in bituminous mixtures. For this purpose, the particle density test was carried out in accordance with the UNE-EN 1097-7 standard, in order to determine whether volumetric corrections are necessary due to a different density of the slag from a conventional aggregate; the sand equivalent test in accordance with the UNE-EN 933-8 standard, to determine the presence of colloidal particles, the broken surface test in accordance with the UNE-EN 933-5 standard and the flakiness index test in accordance with the UNE-EN 933-3 standard, to determine the shape of the particles and their suitability for use in bituminous mixtures intended for high traffic roads. With the aim of determining the resistance of electric arc furnace slag, tests were carried out on resistance to fragmentation in accordance with standard UNE-EN 1097-2, to qualify the hardness of the material and its suitability for high traffic; resistance to freezing and thawing cycles (standard UNE-EN 1367-1), to evaluate the resistance to thermal fatigue of the aggregate; and determination of the value of polished stone (standard UNE-EN 1097-8).

Finally, of the electric arc furnace slags and ladle furnace slags, which account for a high percentage of material within the bituminous mixtures conformed, the concentration of potentially polluting chemical elements in the leaching of these with water was evaluated. This test was carried out in accordance with the UNE-EN 12457-3 standard. If in the analysis of the leachate there were a high concentration of contaminating elements according to the limits set by the regulations, the use of the slag would be unfeasible. However, this fact does not occur as detailed in the subsequent section.

\subsubsection{Conformed of Bituminous Mixtures and Tests}

Once the chemical composition and physical properties of electric arc furnace slag, ladle furnace slag and cellulose fibers have been determined, proceeded to manufactured the different families of bituminous mixtures.

Firstly, the grading of all bituminous mixtures conformed was selected. This grading remains unchanged for the different families, in order to obtain their physical and mechanical properties in the most objective way possible. In this way, the goodness of the incorporation of the detailed waste into the conformed bituminous mixtures can be evaluated. If the grading were modified for the different families of mixtures, variables would be introduced into the methodology that would make it difficult to quantify the properties obtained objectively. The grading curve formed by the coarse aggregate, fine aggregate and filler for all families is shown in Figure 1. This grading curve corresponds to the intermediate grading envelope defined by the Spanish standard Circular Order OC 3/2019 for bituminous mixtures with discontinuous grading and aggregate sizes smaller than $11 \mathrm{~mm}$. 


\section{GRADING CURVE OF BITUMINOUS MIXTURES}

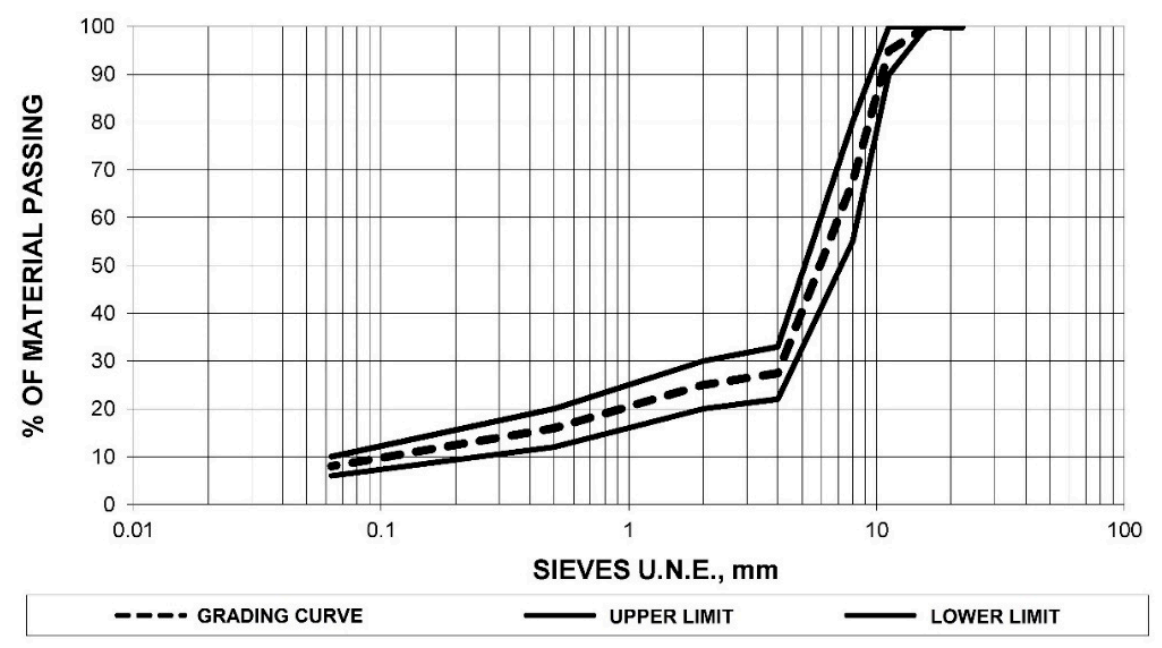

Figure 1. Grading curve of the different families of bituminous mixtures.

Once the grading curve of all the bituminous mixtures proceeded to determined, the different families of bituminous mixtures with conventional materials and waste were defined. In this way, it was possible to objectively evaluate the goodness implied by the incorporation of the waste into the bituminous mixtures conformed. These families of bituminous mixtures are detailed in Table 2.

Table 2. Families of bituminous mixtures conformed with electric arc furnace slag, Hornfels aggregate, ladle furnace slag, calcareous filler, and fibers from the papermaking industry.

\begin{tabular}{cccc}
\hline Samples Groups & HC & SC & SS \\
\hline Coarse aggregate & Hornfels aggregate & EAFS & EAFS \\
Fine Aggregate & Hornfels aggregate & EAFS & EAFS \\
Filler & Calcareous & Calcareous & LFS \\
Additives & Papermaking waste & Papermaking waste & Papermaking waste \\
\hline
\end{tabular}

From each family of bituminous mixtures, with the materials defined in Table 2 and the grading curve detailed in Figure 1, different groups of samples were made with increasing percentages of bitumen. This type of bituminous mixture has a high percentage of bitumen, since the cellulose fibers incorporated make it possible to absorb it. In this way it is possible to obtain mixtures with greater durability and resistance to traction loads. Therefore, different groups of samples of each family were conformed with bitumen percentages from $14 \%$ to $18 \%$ in volume, with $1 \%$ increments of bitumen. It should be noted that these percentages refer to the volume of bitumen over the volume of the aggregates, considering the total volume of the aggregates as the sum of the coarse, fine, and filler aggregates according to the grading curve defined in Figure 1. In turn, it is necessary to point out that the percentages of bitumen are used in volume and not in mass, since the greater density of the slag makes it necessary to use volumetric corrections. If this is not done, the results may not be comparable and may even be detrimental to the final conformed material.

Cellulose fibers were incorporated in an invariable percentage in all families of bituminous mixtures of $1.05 \%$ over the volume of the aggregate. This percentage by volume corresponds to $0.5 \%$ by mass of a conventional aggregate with a density of $2650 \mathrm{~kg} / \mathrm{m}^{3}$.

The bituminous mixtures of the different groups of samples of each family were manufactured with the same operative procedure. To do this, the aggregates (natural or waste) and fibers were heated in an oven to a temperature of $180 \pm 5^{\circ} \mathrm{C}$ for $1 \mathrm{~h}$, as was the bitumen, and then mixed in an automatic planetary mixer for $10 \pm 1 \mathrm{~min}$. The resulting mixture was extracted and compacted at a temperature of $150 \pm 5^{\circ} \mathrm{C}$ by a 
Marshall compactor with 50 blows per side of each sample (standard UNE-EN 12697-30). The conformed specimens were kept at ambient temperature $\left(25 \pm 2{ }^{\circ} \mathrm{C}\right)$ for $24 \mathrm{~h}$ for subsequent by mechanical stripping. A total of 8 Marshall type test samples were made for each percentage of bitumen in each family.

After obtaining the groups of samples, with increasing percentages of bitumen from each family of samples, proceeded to the characterization of the physical properties. The tests carried out were on the maximum density of the bituminous mixture (standard UNEEN 12697-5) and bulk density (standard UNE-EN 12697-6). In turn, the void characteristics of the bituminous mixes obtained was calculated (standard UNE-EN 12697-8).

To evaluate the mechanical resistance of the families of bituminous mixtures conformed, the Marshall test was carried out (standard UNE-EN 12697-14). With this test it was possible to evaluate the plastic deformations that occur in each bituminous mixture, this being an essential characteristic due to the high percentage of bitumen that this type of mixture possesses.

\subsubsection{Determination of Optimal Material Combinations and Comparison of the Results}

Once the results of the physical and mechanical tests of the different groups of samples of each family of bituminous mixtures were obtained, the optimum percentage of bitumen for each family proceeded to determined. This percentage of bitumen by volume was calculated mathematically with the resistance results of the Marshall test. For this purpose, a grade 4 polynomial function was approximated and the percentage of bitumen developing the maximum resistance was calculated. The Marshall test was selected as the potential for determining the optimum bitumen percentage, as it has a high importance within the properties of bituminous mixtures. This is due to the fact that the existence of plastic deformation is the most limiting property of the characteristics of bituminous mixtures with a high percentage of bitumen. However, the optimum percentage of bitumen was selected according to the Marshall test, provided that the other physical properties were adequate according to the limitations established by the Spanish regulations details.

With the optimum combination of materials, of the three families detailed in Table 2, samples were again conformed to repeat the physical and mechanical tests described in the previous section. The compaction and manufacturing process was similar, thus corroborating the results approximate mathematically for the optimum combination of materials.

In purpose of evaluating the durability of the conformed bituminous mixtures, the wheeltracking test, standard UNE-EN 12697-22, was carried out. This test reflects the deformation of bituminous mixtures by the continuous and cyclical passage of a standardized wheel, under certain environmental conditions. In this manner it is easy to objectively qualify the behavior of the various bituminous mixtures by the continuous passage of vehicles.

At the same time, the binder drainage test was carried out for the optimum combination of materials from the three families of bituminous mixtures (standard UNE-EN 12697-18). This test objectively determined the effectiveness of the cellulose fibers discarded from the papermaking industry to absorb higher percentages of binders without causing bleeding problems.

\section{Results and Discussions}

This section details the results of the tests presented in the methodology, as well as the discussions about them. In this way, a series of partial conclusions are obtained that converge in the final conclusion.

\subsection{Characterization of Raw Materials}

As mentioned above, the characterization of the chemical composition and the physical or mechanical properties of the waste is essential for its correct use within the final material. Usually, this type of materials have a series of particularities, that even not being negative, if they must be taken into account for the conformation of a final material of quality. 
Firstly, the discarded cellulose fibers from the papermaking industry were analyzed. These cellulose fibers, as indicated, are the additive used in the different families of bituminous mixtures to absorb a greater percentage of bitumen. They must therefore have a suitable chemical composition. To determine the chemical composition, the elemental analysis test was carried out, detecting the presence of carbon, nitrogen, hydrogen, and sulfur, because it is an organic material. The results of the elemental analysis test are detailed in Table 3.

Table 3. Elemental analysis of cellulose fibers discarded by the Papermaking Industry.

\begin{tabular}{ccccc}
\hline Sample & Nitrogen, $\%$ & Carbon, $\%$ & Hydrogen, $\%$ & Sulfur, $\%$ \\
\hline Fibers & $0.447 \pm 0.008$ & $44.489 \pm 0.325$ & $5.884 \pm 0.178$ & $0.000 \pm 0.000$ \\
\hline
\end{tabular}

As can be seen, the elemental analysis test reflects the composition of an organic material. The percentage of carbon and hydrogen demonstrate such a composition. On the other hand, the low nitrogen and sulfur values reflect the material's suitability for use in bituminous mixtures, since otherwise these pollutant elements could damage the bituminous mixture and produce polluting leachate. It should be noted that the sum of the elements analyzed does not correspond to $100 \%$. This is due to the fact that the fibers have been washed with sodium hydroxide, so this chemical element has been retained in the matrix of the fibers without prejudice to the final material.

In turn, the cellulose fibers must be distributed homogeneously in the conformed bituminous mixtures to avoid the production of bleeding. In addition, they must be of an appropriate size for the correct formation of a mastic capable of resisting the traction loads of traffic. Therefore, the scanning electron microscope test was carried out to the aim to evaluate the size of the fibers. The images taken from this test are detailed in Figure 2.

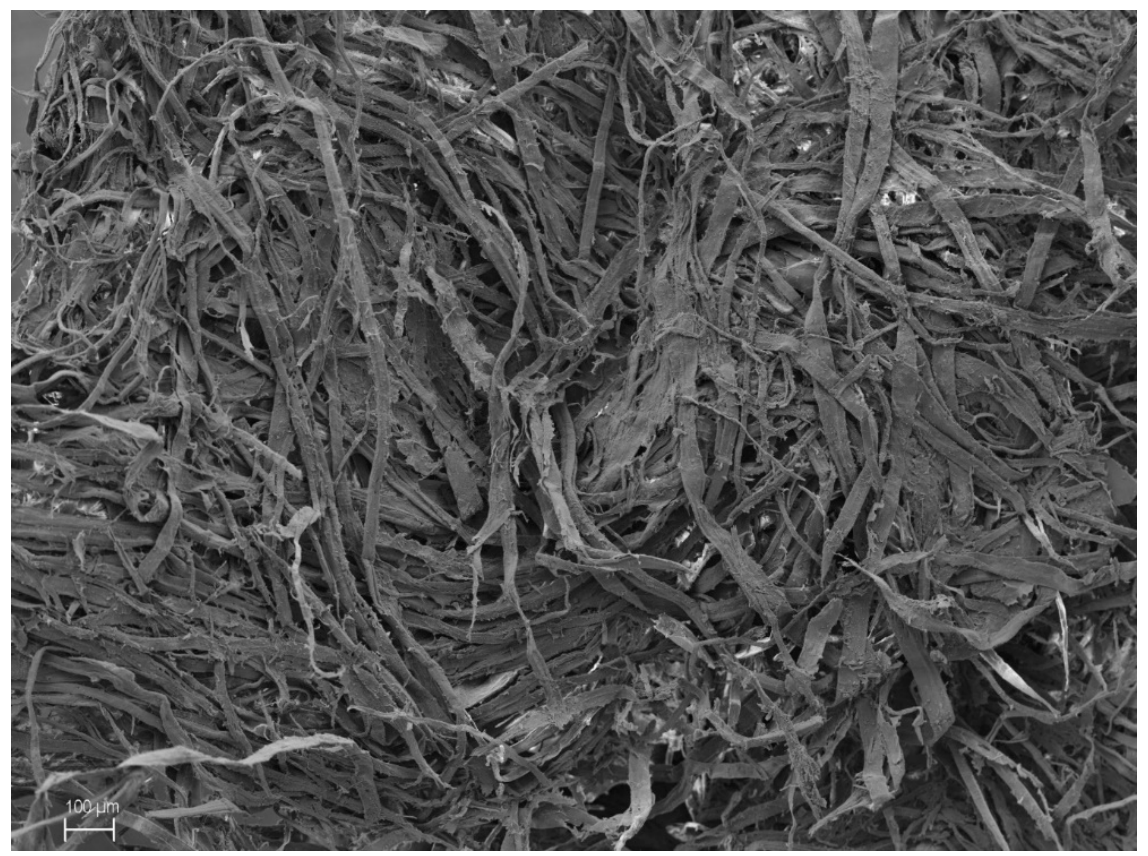

Figure 2. Image of the cellulose fibers of the Paper Industry obtained with the Scanning Electron Microscope in the secondary option.

Figure 2 shows a millimeter size of cellulose fiber. This fiber size is ideal for use in bituminous mixtures, as larger sizes would make the mixing process more difficult. At the same time, it can be seen that there are no agglomerations of cellulose fibers that could be detrimental to the correct homogenization in bituminous mixtures. If this were not the case, bitumen bleeding and heterogeneities in the properties of the mixtures conformed 
could be produced. Therefore, the suitability of the fibers for the correct absorption of a higher percentage of bitumen into the bituminous mixtures was demonstrated through the above-mentioned tests.

After evaluating the cellulose fibers, the chemical composition of the ladle furnace slag was determined. To do this, the elemental analysis test was first carried out, reflecting the results shown in Table 4.

Table 4. Elemental analysis of the ladle furnace slag.

\begin{tabular}{ccccc}
\hline Sample & Nitrogen, $\%$ & Carbon, $\%$ & Hydrogen, $\%$ & Sulfur, $\%$ \\
\hline LFS & $0.007 \pm 0.001$ & $3.405 \pm 0.068$ & $1.386 \pm 0.026$ & $0.000 \pm 0.000$ \\
\hline
\end{tabular}

The elemental analysis test showed the absence of harmful and polluting elements such as nitrogen and sulfur, and therefore their suitability for use in bituminous mixtures was confirmed. In turn, the percentage of carbon and hydrogen of the ladle furnace slag seems to correspond with high probability to the carbonation and hydration of different chemical compounds, not being a harmful fact but to be taken into account.

Given the mainly inorganic composition of the ladle furnace slag, the elemental composition was determined by means of the X-ray fluorescence test. This test reflected the results shown in Table 5.

Table 5. Results of the X-ray fluorescence of ladle furnace slag.

\begin{tabular}{ccc}
\hline Compound & wt, $\%$ & Est. Error \\
\hline $\mathrm{CaO}$ & 40.19 & 0.25 \\
$\mathrm{MgO}$ & 19.38 & 0.20 \\
$\mathrm{SiO}_{2}$ & 12.49 & 0.17 \\
$\mathrm{Al}_{2} \mathrm{O}_{3}$ & 7.29 & 0.13 \\
$\mathrm{Fe}_{2} \mathrm{O}_{3}$ & 2.38 & 0.08 \\
$\mathrm{MnO}$ & 0.936 & 0.047 \\
$\mathrm{~S}$ & 0.548 & 0.027 \\
$\mathrm{TiO}_{2}$ & 0.486 & 0.024 \\
$\mathrm{BaO}$ & 0.240 & 0.012 \\
$\mathrm{Na}_{2} \mathrm{O}$ & 0.118 & 0.042 \\
$\mathrm{Cr}_{2} \mathrm{O}_{3}$ & 0.1100 & 0.0055 \\
$\mathrm{Cl}$ & 0.0833 & 0.0042 \\
$\mathrm{SrO}$ & 0.0733 & 0.0037 \\
$\mathrm{ZnO}_{\mathrm{K}_{2} \mathrm{O}}$ & 0.0681 & 0.0034 \\
$\mathrm{ZOO}_{2}$ & 0.0506 & 0.0025 \\
$\mathrm{~V}_{2} \mathrm{O}_{5}$ & 0.0425 & 0.0021 \\
$\mathrm{P}$ & 0.0179 & 0.0017 \\
$\mathrm{CuO}$ & 0.0138 & 0.0012 \\
$\mathrm{NiO}$ & 0.0117 & 0.0010 \\
$\mathrm{PbO}^{\mathrm{Nb}} \mathrm{O}_{5}$ & 0.0082 & 0.0011 \\
$\mathrm{MoO}_{3}$ & 0.0048 & 0.0010 \\
$\mathrm{Co}_{3} \mathrm{O}_{4}$ & 0.0046 & 0.0006 \\
$\mathrm{SeO}_{2}$ & 0.0028 & 0.0009 \\
& 0.0021 & 0.0009 \\
\end{tabular}

The X-ray fluorescence of the ladle furnace slag showed an elemental composition consisting mainly of the chemical elements calcium, magnesium, silicon, and aluminum. The presence of these elements is logical, since they come directly from the steel production process and consequently from the ladle furnace slag. In the refining stage of the metallurgical industry, lime or dolomites are added in order to eliminate impurities through the formation of this slag; therefore, the ladle furnace slag has the chemical composition of the added elements. On the other hand, the existence of iron in the sample is obvious, as the slag comes from a steel production process. The rest of the chemical elements are in 
low proportion and do not condition the characteristics of the final material. However, the leachate test was subsequently carried out to evaluate the concentration of these chemical elements and to determine whether they could produce environmental pollution. It should be noted that the $X$-ray fluorescence test provides an elemental composition. This elemental composition may be reflected in the form of oxides; however, it does not imply that these oxides actually exist in the sample.

For the determination of the main chemical compounds, the X-ray diffraction test was performed, reflecting the diffractogram shown in Figure 3.

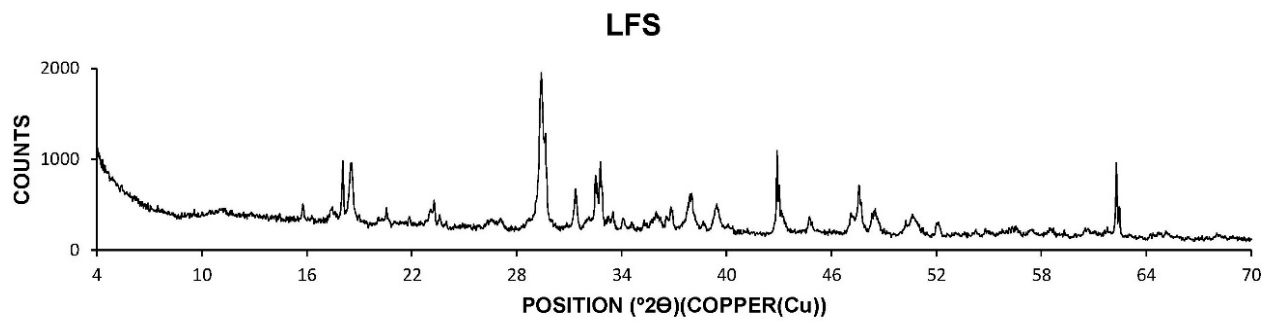

Figure 3. Results of X-ray diffraction of ladle furnace slag.

Analysis of the diffractogram obtained from the X-ray diffraction test of ladle furnace slag shows the high content of amorphous or non-diffractant material. Calcite, olivine, and periclase are identified as the main phases. In turn, different silicates are also identified in smaller proportions, including magnesium silicate. This fact ensures that the slags studied do not have expansive characteristics, since magnesium oxide is not found in the sample. The elemental magnesium identified in the X-ray fluorescence test appears combined in the form of silicates, so that its structure is more stable and does not condition expansion problems.

Considering that ladle furnace slag will act as a filler in bituminous mixtures, a series of physical properties must be determined in order to ensure its quality. Firstly, the grading curve of the ladle furnace slag was analyzed as it comes from the production industry. This grading curve is detailed in Figure 4.

\section{LADLE FURNACE SLAG GRADING CURVE}

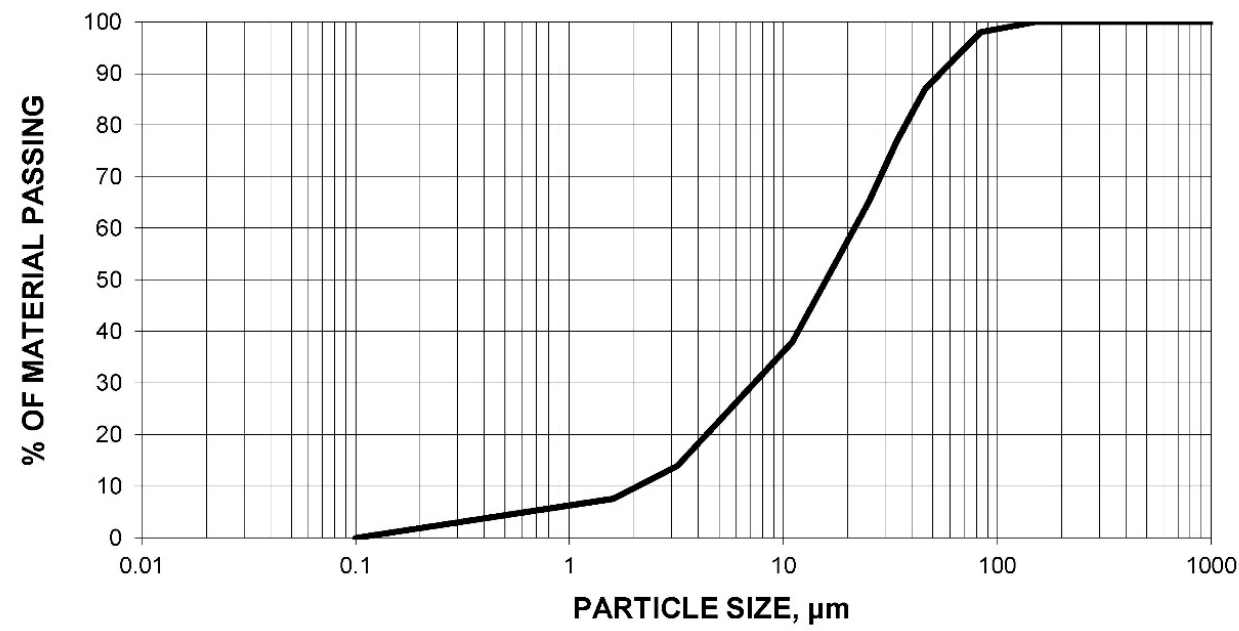

Figure 4. Grading curve of the ladle furnace slag received from the production industry without sieving through the $0.063 \mathrm{~mm}$ sieve.

As can be seen in Figure 4, the particle size of ladle furnace slag as received from the production industry and unaltered has a high percentage of particles smaller than $0.063 \mathrm{~mm}$. Therefore, its use as a filler in bituminous mixtures is suitable. 
In addition, a series of physical properties were analyzed which are essential for evaluating the suitability of a material which performs the function of a filler in bituminous mixtures. These physical properties of the ladle furnace slag are detailed in Table 6 .

Table 6. Density and plasticity tests for the fine portion of ladle furnace slag.

\begin{tabular}{ccc}
\hline Test & Standard & Value/Unit \\
\hline Particle density & UNE-EN 1097-7 & $2.71 \pm 0.07 \mathrm{t} / \mathrm{m}^{3}$ \\
Bulk density & UNE-EN 1097-3 & $0.75 \pm 0.01 \mathrm{t} / \mathrm{m}^{3}$ \\
Plasticity index & UNE 103103/UNE 103104 & No plasticity \\
\hline
\end{tabular}

The particle density of the ladle furnace slag does not differ greatly from that of a commercial filler, $2650 \mathrm{~kg} / \mathrm{m}^{3}$, so no volumetric corrections are necessary. In turn, the bulk density of the slag studied reflects an acceptable result, not being qualified as a powdery material. Finally, the null plasticity index of the ladle furnace slag shows the inexistence of particles that could cause subsequent expansion problems, such as clayey particles.

Based on the above, it can be established that the chemical composition and physical properties of the ladle furnace slag are suitable for use as filler in bituminous mixtures.

On the other hand, the electric arc furnace slags were analyzed chemically. For this purpose, the elemental analysis test was first carried out. The results of this test are shown in Table 7.

Table 7. Elemental analysis of the electric arc furnace slag.

\begin{tabular}{ccccc}
\hline Sample & Nitrogen, $\%$ & Carbon, $\%$ & Hydrogen, $\%$ & Sulfur, $\%$ \\
\hline EAFS & $0.005 \pm 0.001$ & $0.164 \pm 0.003$ & $0.044 \pm 0.001$ & $0.000 \pm 0.001$ \\
\hline
\end{tabular}

The elemental analysis test reflected the chemical composition of an inorganic material, existing low percentages of carbon and hydrogen. At the same time, the inexistence of nitrogen and sulfur was reflected, demonstrating the non-production of polluting lixiviates of these chemical elements.

As it is an inorganic material, the X-ray fluorescence test was carried out in order to quantitatively determine the presence of the rest of the chemical elements not analyzed in the elemental analysis. The results of this test are shown in Table 8.

The chemical composition of the electric arc furnace slag is directly derived from its production process. Therefore, there are high percentages of iron, as it is the main element of steel, as well as calcium, a chemical element present in the additive to the molten liquid for the formation of the slag. In turn, silicon and aluminum are common elements present in the scrap that is used to manufacture steel. Magnesium, manganese, and chromium are also common in the composition of steels. The other elements are found in such a reduced proportion that they do not produce modifications in the properties of the final material. However, the leachate test was subsequently carried out to verify that the concentration of the polluting chemical elements is below the limits set by the regulations.

Once the elemental composition had been determined, the main chemical compounds were identified through the X-ray diffraction test. The diffractogram derived from the $X$-ray diffraction test of the electric arc furnace slag is shown in Figure 5. 
Table 8. X-ray fluorescence of electric arc furnace slag.

\begin{tabular}{|c|c|c|}
\hline Compound & $W t, \%$ & Est. Error \\
\hline $\mathrm{CaO}$ & 31.75 & 0.23 \\
\hline $\mathrm{Fe}_{2} \mathrm{O}_{3}$ & 21.96 & 0.21 \\
\hline $\mathrm{SiO}_{2}$ & 17.52 & 0.19 \\
\hline $\mathrm{Al}_{2} \mathrm{O}_{3}$ & 12.26 & 0.16 \\
\hline $\mathrm{MnO}$ & 6.15 & 0.12 \\
\hline $\mathrm{MgO}$ & 5.05 & 0.11 \\
\hline $\mathrm{Cr}_{2} \mathrm{O}_{3}$ & 2.73 & 0.08 \\
\hline $\mathrm{TiO}_{2}$ & 0.955 & 0.047 \\
\hline $\mathrm{BaO}$ & 0.658 & 0.033 \\
\hline $\mathrm{P}_{2} \mathrm{O}_{5}$ & 0.319 & 0.016 \\
\hline $\mathrm{SrO}$ & 0.186 & 0.0093 \\
\hline $\mathrm{V}_{2} \mathrm{O}_{5}$ & 0.159 & 0.0079 \\
\hline $\mathrm{Nb}_{2} \mathrm{O}_{5}$ & 0.0659 & 0.0033 \\
\hline S & 0.0645 & 0.0032 \\
\hline $\mathrm{ZrO}_{2}$ & 0.0551 & 0.0028 \\
\hline $\mathrm{K}_{2} \mathrm{O}$ & 0.0289 & 0.0016 \\
\hline $\mathrm{CuO}$ & 0.0254 & 0.0017 \\
\hline $\mathrm{ZnO}$ & 0.0245 & 0.0016 \\
\hline $\mathrm{Co}_{3} \mathrm{O}_{4}$ & 0.0147 & 0.0016 \\
\hline $\mathrm{Eu}_{2} \mathrm{O}_{3}$ & 0.0137 & 0.0065 \\
\hline $\mathrm{WO}_{3}$ & 0.0104 & 0.0031 \\
\hline $\mathrm{Y}_{2} \mathrm{O}_{3}$ & 0.0018 & 0.0005 \\
\hline
\end{tabular}

EAFS

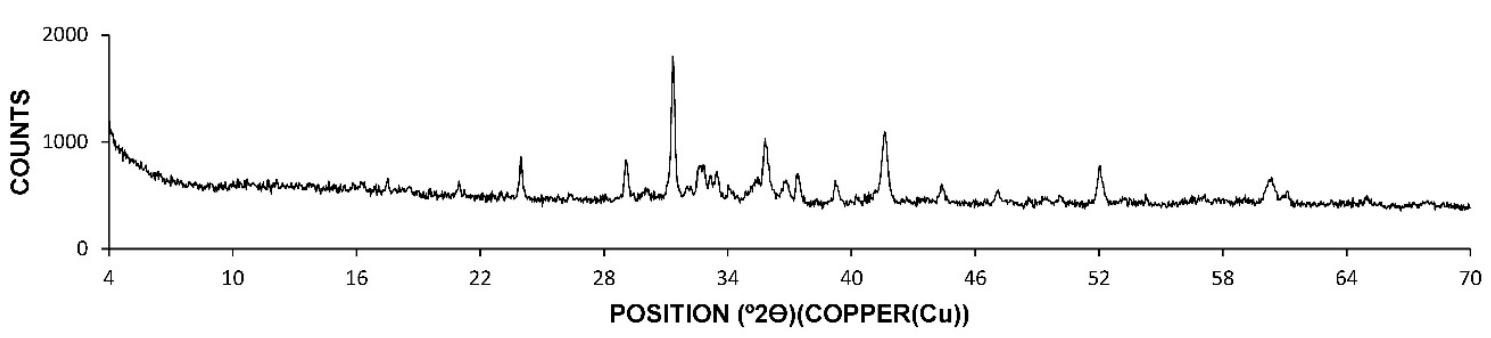

Figure 5. Results of X-ray diffraction of electric arc furnace slag.

The diffractogram of the electric arc furnace slag reflected the high content of amorphous or non-diffracting material. Iron oxide and mixed iron and manganese oxides were identified as the main phases. Wollastonite was also identified in a smaller proportion. Therefore, and unlike the ladle furnace slag, the results reflect the chemical composition of a much more stable material in which the chemical compounds present do not lead to variations in shape. In other words, the expansiveness of these electric arc furnace slags is non-existent.

Subsequently, after determining the chemical composition of the electric arc furnace slag, the physical properties of the slag proceeded to evaluate. The electric arc furnace slag performs the function of a coarse and fine aggregate in the bituminous mixture, which is why the tests carried out are those detailed in Table 9. 
Table 9. Density and plasticity tests for the fine portion of ladle furnace slag.

\begin{tabular}{ccc}
\hline Test & Standard & Value/Unit \\
\hline Particle density (coarse aggregate) & UNE-EN 1097-7 & $3.13 \pm 0.05 \mathrm{t} / \mathrm{m}^{3}$ \\
Particle density (fine aggregate) & UNE-EN 1097-7 & $3.34 \pm 0.07 \mathrm{t} / \mathrm{m}^{3}$ \\
Sand Equivalent test & UNE-EN 933-8 & $77 \pm 2 \%$ \\
Broken surfaces (coarse aggregate) & UNE-EN 933-5 & $100 \pm 1 \%$ \\
Flakiness index & UNE-EN 933-3 & $0 \pm 1 \%$ \\
\hline
\end{tabular}

Physical testing of the electric arc furnace slag showed that the density of the particles was higher than that of a conventional aggregate, considering as the norm that the density of a conventional aggregate is $2650 \mathrm{~kg} / \mathrm{m}^{3}$. This fact, although it is not a problem, must be taken into account for the proportioning of the materials, so that volumetric corrections are necessary. If these corrections were not made, the properties of the final material could be damaged. At the same time, the sand equivalent test reflected the low proportion of colloidal particles, not producing subsequent problems of expansiveness. It is worth noting the excellent results obtained in the broken surfaces and flakiness index tests. These results reflect the singular shape of the electric arc furnace slag particles, with a multitude of sharp edges and similar dimensions in all three axes. They are therefore ideal for use in bituminous mixtures with discontinuous grading where the compressive loads of traffic are supported by internal friction of the particles.

At the same time, it should be noted that bituminous mixtures with discontinuous grading have a series of advantages over mixtures with continuous grading, mainly a higher void content. However, this discontinuous grading makes it necessary for the coarse aggregate to be of high quality, since it is the main responsible for supporting the compressive loads of traffic. Therefore, the coarse aggregate must have adequate shape and mechanical characteristics. The shape characteristics of the particles of the electric arc furnace slag have already been defined previously, so it is necessary to corroborate the mechanical resistance.

This mechanical resistance has been evaluated through the test of resistance to fragmentation and resistance to freezing-thawing cycles, reflecting values of $13 \pm 1 \%$ and $0.551 \pm 0.016 \%$ respectively. At the same time, it is essential that the aggregates provide an adequate macrotexture and microtexture for a correct friction between the tire and the pavement. This property is evaluated with the determination test of the polished stone. This test reflected a value of $58 \pm 1$, demonstrating the correct resistance in time of the aggregates and ensuring the roughness of the pavement during its working life.

Finally, and to corroborate that high concentrations of chemical pollutants are not leached, the leachates from the electric arc furnace and ladle furnace slags were analyzed in accordance with the UNE-EN 12457-3 standard. The results of the leachings of the different chemical elements are detailed in Table 10.

The concentration of the chemical elements in the leaching of electric arc furnace slag and ladle furnace slag does not exceed the limits established by Spanish regulations, since the heavy metals analyzed are in low proportion in both industrial by-products. Therefore, it can be assured that there will be no subsequent pollution problems from the use of the slags and that their use for bituminous mixtures is acceptable. 
Table 10. Concentration of chemical elements in the leaching of ladle furnace slag and electric arc furnace slag.

\begin{tabular}{ccc}
\hline Element & LFS, $\mathbf{~ g} / \mathbf{k g}$ & EAFS, $\mathbf{~ g} / \mathbf{k g}$ \\
\hline $\mathrm{Ba}$ & 12.784 & 2.132 \\
$\mathrm{Cd}$ & 0.000 & 0.000 \\
$\mathrm{Cr}$ & 0.007 & 0.237 \\
$\mathrm{Mo}$ & 0.092 & 0.078 \\
$\mathrm{Ni}$ & 0.002 & 0.004 \\
$\mathrm{~Pb}$ & 0.018 & 0.006 \\
$\mathrm{Se}$ & 0.080 & 0.035 \\
$\mathrm{~V}$ & 0.008 & 1.175 \\
$\mathrm{Zn}$ & 0.021 & 0.112 \\
$\mathrm{As}$ & 0.000 & 0.000 \\
$\mathrm{Cu}$ & 0.066 & 0.105 \\
$\mathrm{Hg}$ & 0.000 & 0.000 \\
$\mathrm{Sb}$ & 0.011 & 0.012 \\
\hline
\end{tabular}

\subsection{Conforming of Bituminous Mixtures and Tests}

Once the physical properties and chemical composition of the waste had been determined, as well as their suitability for conforming to bituminous mixtures, the different families of mixtures detailed in Table 2 proceeded to conform with increasing percentages of bitumen. The procedure for forming and compacting is the detailed in the methodology.

The different families of bituminous mixtures were tested to determine their physical properties. Firstly, the bulk density was calculated, showing the results detailed in Figure 6.

\section{BULK DENSITY VS. \% BITUMEN}

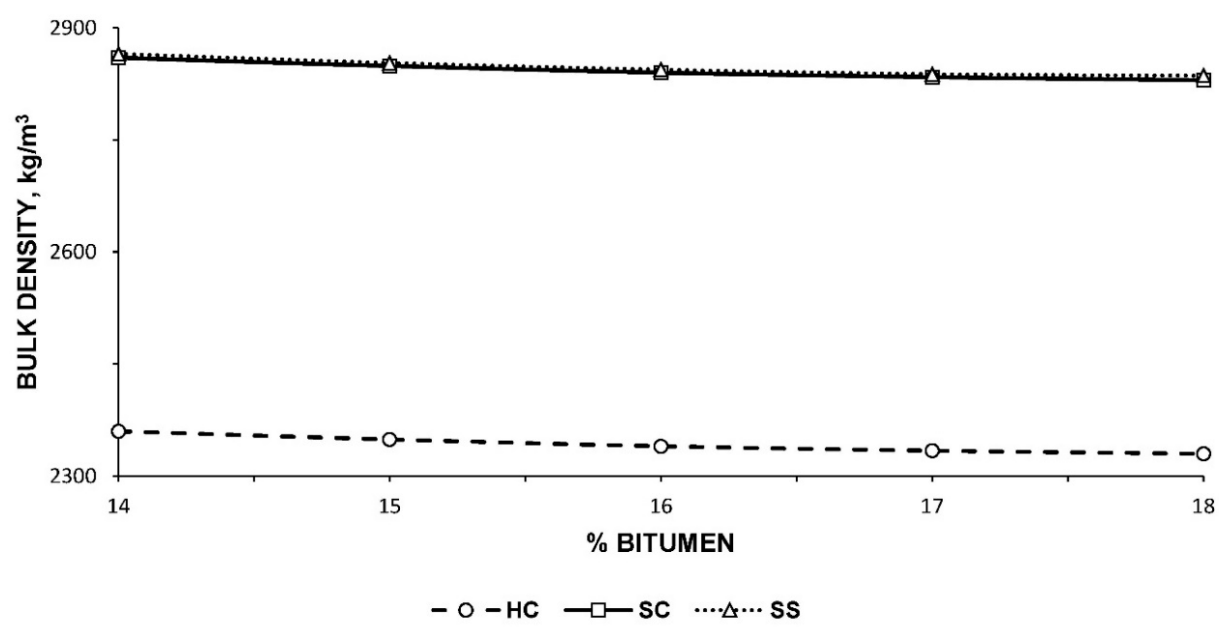

Figure 6. Bulk density of the HC, SC, and SS families of bituminous mixtures according to the percentage of bitumen.

The bulk density is the density of the bituminous mix considering the volume of voids. Therefore, it can be seen that the HC family conformed with conventional materials has a lower bulk density than the SC and SS families. The latter families have very similar bulk densities, because only the filler employed varies.

In turn, the maximum density is another of the essential physical properties for evaluating a bituminous mixture and obtaining the void content. The maximum density of the different families of mixtures with different percentages of bitumen is shown in Figure 7. 
MAXIMUM DENSITY VS. \% BITUMEN

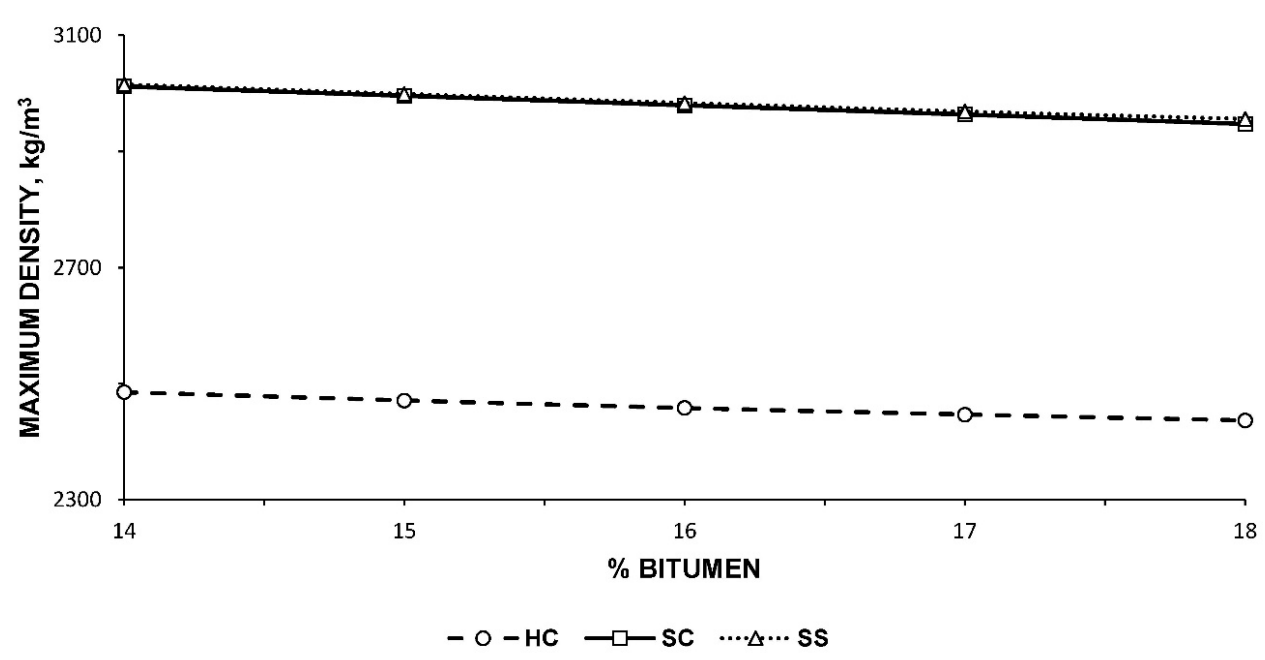

Figure 7. Maximum density of the $\mathrm{HC}, \mathrm{SC}$, and SS families of bituminous mixtures according to the percentage of bitumen.

The maximum density is the density of the bituminous mix without consideration of the voids in the mix. Therefore, and since electric arc furnace slag has a higher density than hornfels aggregate, the SC and SS mix families have a higher maximum density than the $\mathrm{HC}$ family. In turn, it can be seen that the increase in the percentage of binder causes the maximum density for all families to decrease, a fact that can be expected by the low density of the bitumen.

On the other side, the determination of the void content in the mix from the maximum density and the bulk density is essential. The void content is reflected in Figure 8 for all families of bituminous mixtures.

VOID CONTENT VS. \% BITUMEN

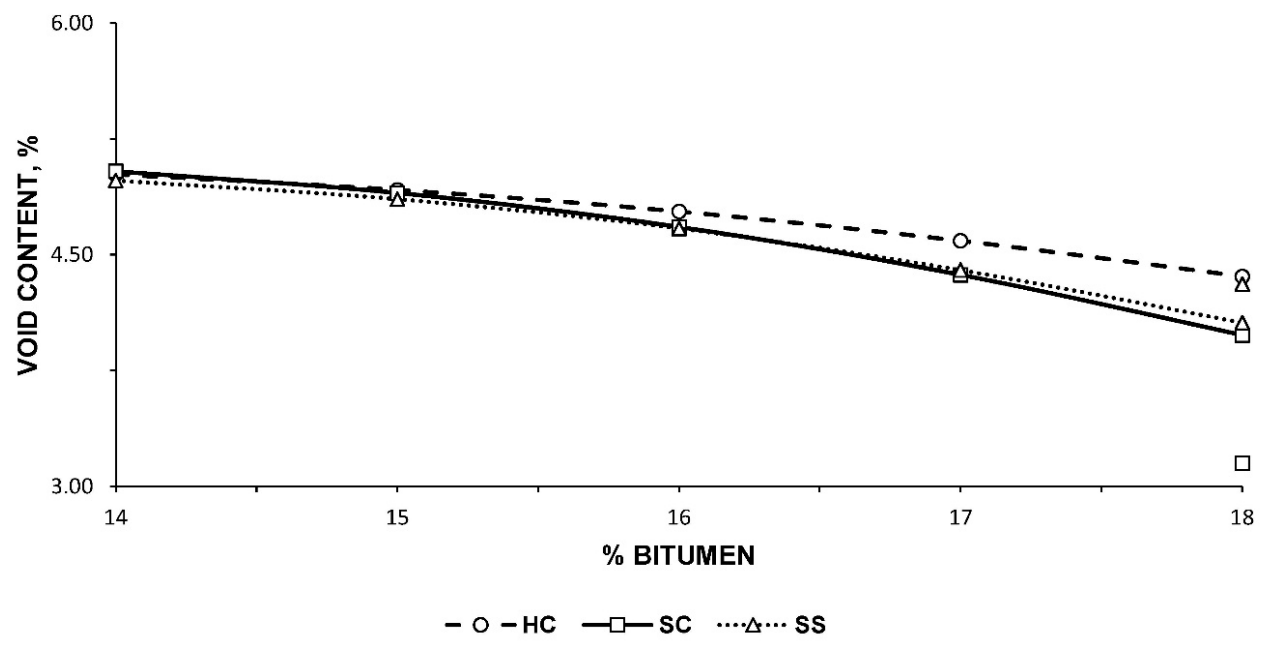

Figure 8. Void content of the HC, SC, and SS families of bituminous mixtures as a percentage of bitumen.

The void content in the mix of the three families of bituminous mixtures is very similar, with small variations in the highest percentages of bitumen between the HC mix and the SC and SS mixes. However, these variations are negligible. It should be noted that the content of voids in the mix is one of the properties that most influences the quality of the bituminous mix, since it conditions its drainability, its roughness for the friction of 
the tire with the pavement, and even the absorption of noise. The values obtained for all the families of bituminous mixtures are acceptable according to the detailed Spanish regulations and are usual in mixtures with discontinuous grading.

The Marshall test was used to evaluate the resistance of the bituminous mixtures. This test evaluates whether the percentage of bitumen is inadequate, creating excessive plastic deformations due to an excess of bitumen, or low resistance due to insufficient bitumen. The Marshall results of the families of conformed mixtures are detailed in Figure 9.

FORCE VS. \% BITUMEN

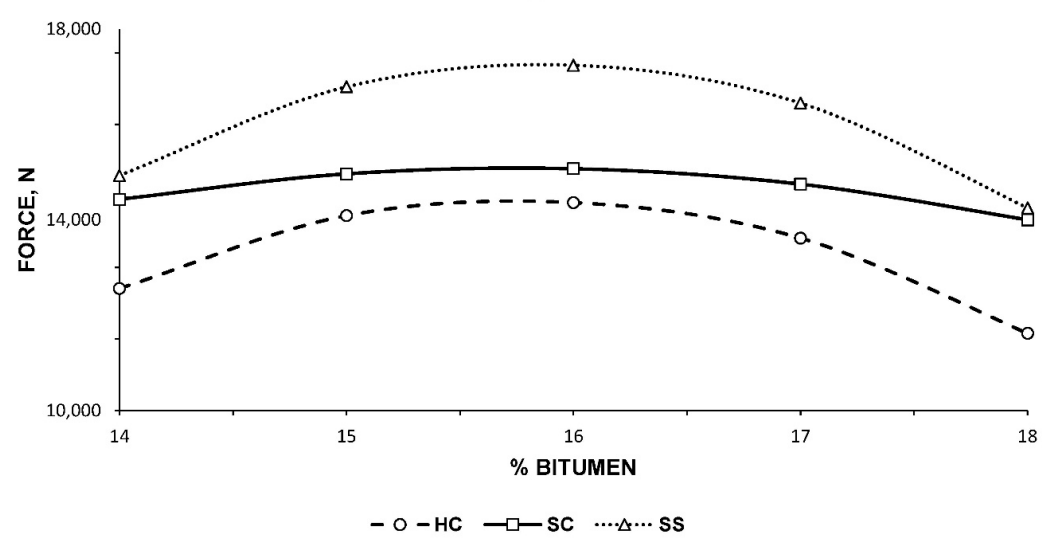

Figure 9. Marshall stability of the HC, SC, and SS families of bituminous mixtures according to the percentage of bitumen.

The Marshall test of the bituminous mix families showed that the SS family, composed of electric arc furnace slag as an aggregate and ladle furnace slag as a filler, had the best resistance. Next, the SC family conformed with calcareous filler has a lower resistance, and lastly, the family of bituminous mixtures conformed with commercial materials HC. This variation in the Marshall resistance of the different families of bituminous mixtures confirms, on the one hand, that the use of electric arc furnace slag allows acceptable results to be obtained, and, on the other hand, that the incorporation of ladle furnace slag as filler makes it possible to obtain resistances that are much higher than those of calcareous filler. It should be noted that the high percentages of bitumen obtained in the three families of bituminous mixtures are due to the addition of discarded cellulose fibers from the papermaking industry. Obtaining adequate resistances and high percentages of bitumen corroborate the suitability of cellulose fibers as an additive for this purpose.

The Marshall test also makes it possible to obtain the deformation or displacement of bituminous mixtures at the time of their breakage. The Marshall deformation of all the families of bituminous mixtures conformed is detailed in Figure 10.

The Marshall deformations of the different families of samples reflect how the filler family of ladle furnace slags, SS, presents a lower deformation. This fact corroborates the rigidity of this mixture and its strength, as well as the cementitious properties of the ladle furnace slag. Next, the family conformed of electric arc furnace slag and calcareous filler SC has intermediate deformations between the two families, also showing acceptable results. Finally, the HC family of samples conformed to conventional materials obtains values of over $3 \mathrm{~mm}$ of deformation in the highest percentages of bitumen. These values are higher than those regulated by the standards and therefore limited for use. 
DISPLACEMENT VS. \% BITUMEN

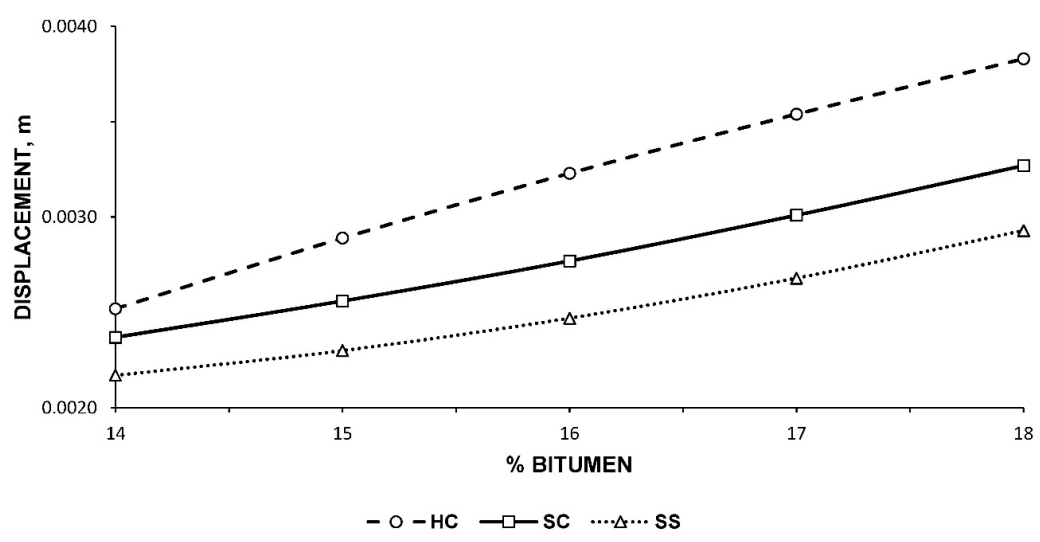

Figure 10. Marshall deformation of the HC, SC, and SS families of bituminous mixtures according to the percentage of bitumen.

\subsection{Determination of Optimal Material Combinations and Comparison of Results}

Once the physical and mechanical properties of the different families of bituminous mixtures with increasing binder percentages had been determined, the optimum bitumen percentage was chosen. This percentage was selected on the basis of the results of the Marshall test, choosing the percentage of bitumen that developed the greatest resistance. The choice of this test to obtain the optimum combination of materials is mainly based on the fact that this is the test that most conditions the quality of the bituminous mix, since the high percentages of bitumen in the mixes are prone to the formation of plastic deformations. However, the choice of the percentage of bitumen for each family as the maximum of the Marshall stability was decided as long as the other properties of the conformed mixtures were acceptable.

As discussed, Table 11 shows the results of the optimum bitumen percentages for each family, as well as the physical and mechanical properties obtained for each combination. These properties were obtained after conforming and testing various samples with the optimum combination of materials for each family.

Table 11. Results of the tests for the optimum combination of materials from the HC, SC, and SS families of bituminous mixtures.

\begin{tabular}{|c|c|c|c|c|}
\hline Test & Standard & $\mathrm{HC}$ & SC & SS \\
\hline $\begin{array}{l}\text { \% bitumen in } \\
\text { volume }\end{array}$ & - & 15.79 & 15.75 & 15.87 \\
\hline $\begin{array}{l}\text { Bulk density, } \\
\mathrm{kg} / \mathrm{m}^{3}\end{array}$ & UNE-EN 12697-6 & $2342 \pm 60$ & $2842 \pm 87$ & $2846 \pm 92$ \\
\hline $\begin{array}{c}\text { Maximum } \\
\text { density, } \mathrm{kg} / \mathrm{m}^{3}\end{array}$ & UNE-EN 12697-5 & $2460 \pm 63$ & $2983 \pm 97$ & $2986 \pm 78$ \\
\hline Void content, \% & UNE-EN 12697-8 & $4.81 \pm 0.17$ & $4.74 \pm 0.15$ & $4.70 \pm 0.16$ \\
\hline $\begin{array}{c}\text { Stability } \\
\text { Marshall, N }\end{array}$ & $\begin{array}{l}\text { UNE-EN } \\
12697-14\end{array}$ & $14,444 \pm 370$ & $15,084 \pm 471$ & $17,290 \pm 516$ \\
\hline $\begin{array}{c}\text { Marshall } \\
\text { Deformation, } \mathrm{m}\end{array}$ & $\begin{array}{l}\text { UNE-EN } \\
12697-14\end{array}$ & $0.0030 \pm 0.0001$ & $0.0027 \pm 0.0001$ & $0.0025 \pm 0.0001$ \\
\hline
\end{tabular}

The percentages of optimum bitumen for the three families of bituminous mixtures are very similar; however, the percentage is slightly higher for the SS family. This is due to the greater specific surface area of the ladle furnace slag which allows a higher percentage of bitumen to be absorbed, as mixtures conformed with electric furnace slag and hornfels aggregate obtain similar percentages. The bulk density and maximum density are higher for mixtures conformed with electric arc furnace slag due to the higher density of this 
material; however, the void content is similar in all three families and acceptable according to the regulations.

It can be seen how the Marshall stability is far superior in the mix conformed with electric arc furnace and ladle furnace slags, demonstrating the excellent properties of ladle furnace slags as fillers in hot mix asphalt. This fact is corroborated with a lower Marshall deformation, showing a material of high rigidity and resistance. In turn, the Marshall stability of the samples conformed with electric arc furnace slag is superior to that of hornfels aggregate, as it reflects higher values and lower deformations. The goodness of electric arc furnace slag and ladle furnace slag in hot mix asphalt is therefore demonstrated.

Finally, and with the aim of corroborating the durability of the families of bituminous mixtures over time, the wheel-tracking test was carried out. This test measures the deformation produced in the bituminous mix by the continuous passage of a standardized wheel with load during thousands of cycles. The results of this test are shown in Figure 11.

\section{WHEEL TRACKING TEST}

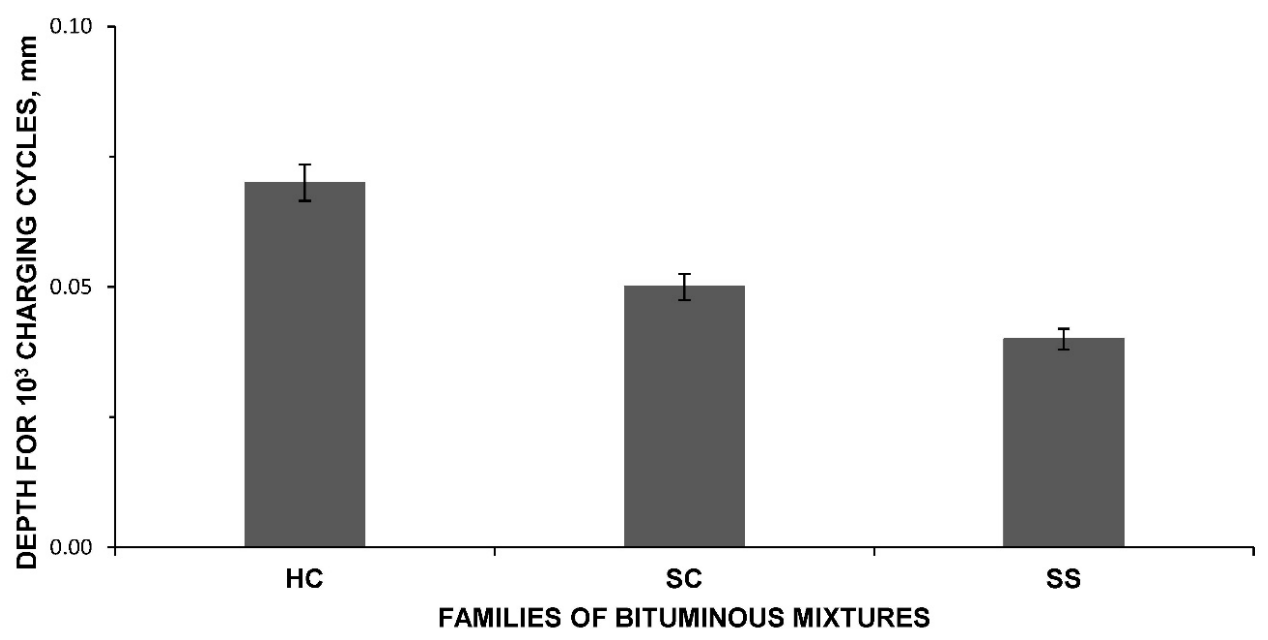

Figure 11. Wheel-tracking test for the optimum combination of materials from the HC, SC, and SS families of bituminous mixtures.

The wheel-tracking test reflects how the bituminous mix conformed with electric arc furnace slag and ladle furnace slag has less deformation after the test, demonstrating the rigidity, strength, and durability previously determined by the Marshall test. Electric arc furnace slag also provides durable bituminous mixes as shown in Figure 11. The HC bituminous mix, even having a higher deformation, develops acceptable results, corresponding to a quality bituminous mix.

In turn, the binder drainage test determined that no binder bleeding occurred in any of the three families of bituminous mixtures formed with the optimal combination of materials. Therefore, the effectiveness of discarded cellulose fibers from the papermaking industry as an additive to absorb a higher percentage of bitumen was confirmed.

In short, it can be said that the results reflect the quality of bituminous mixtures for use as a wearing course on roads with high traffic, reflecting even better results the family of bituminous mixtures conformed with electric arc furnace slag, ladle furnace slag, and cellulose fibers.

\section{Conclusions}

The partial conclusions defined, based on the results of the tests mentioned in the methodology, lead to the verification of the final conclusion of the investigation. Therefore, we proceed to the definition of the partial conclusions:

- The cellulose fibers discarded from the papermaking industry have a mainly organic chemical composition, with very low or non-existing chemical element pollutants, 
such as nitrogen or sulfur. Furthermore, these cellulose fibers are millimetric in size and are disaggregated, making it possible for them to be homogenized in the bituminous mixture.

- Ladle furnace slag has a chemical composition consisting mainly of silicates and calcium oxide. This composition is responsible for the cementitious characteristics. At the same time, the slag has a particle density similar to that of a commercial filler, with a suitable specific surface and without the presence of plasticity.

- Electric arc furnace slag has a chemical composition consisting mainly of iron oxides and wollastonite. This chemical composition conditions their higher particle density, as well as a resistance to fragmentation, to the freezing-thawing cycles and high resistance to polishing. It is worth noting the absence of colloidal particles and its excellent shape for mixtures with discontinuous grading.

- Leachate from electric arc furnace slags and ladle furnace slags have concentrations of chemical elements pollutants that are lower than those required by regulations. Their use for bituminous mixtures is therefore not an environmental problem.

- Discarded cellulose fibers from the papermaking industry allow higher percentages of bitumen to be absorbed in all families of bituminous mixtures without presenting problems of binder bleeding. These fibers therefore form a quality mastic with the filler and bitumen capable of withstanding the traction loads of traffic.

- The void content in the mix of the families conformed with electric arc furnace slag and ladle furnace slag is similar to that of traditional mixtures.

- The utilization of electric arc furnace slag, as a coarse and fine aggregate for bituminous mixtures, provides greater Marshall stability, preventing the formation of plastic deformations. In addition, the employment of this by-product creates mixtures of greater durability as reflected in the wheel-tracking test

- The use of ladle furnace slag as filler for hot mix asphalt provides excellent Marshall stability, with reduced deformations. The cementitious properties of this by-product are therefore confirmed, creating durable and resistant materials as demonstrated by the wheel-tracking test.

On the basis of the partial conclusions it can be concluded that electric arc furnace slag and ladle furnace slag create more resistant bituminous mixtures, less likely to produce plastic deformation and more durable over time. In addition, the incorporation of cellulose fibers from the papermaking industry makes it possible to form a higher quality mastic without the production of bleeding. Therefore, this type of bituminous mixture can be used as a wearing course on high traffic roads.

In short, this research shows the potential that exists in industrial by-products. These by-products or wastes, properly characterized and used in the ideal element of the bituminous mixture, can create sustainable materials with superior characteristics to those of conventional materials. At the same time, it is important to highlight the importance of the use of waste; on the one hand, it reduces the deposition of waste in landfills; on the other hand, it avoids the extraction of new raw materials; and finally, it provides a new life to that material.

Author Contributions: Conceptualization, F.A.C.-I., F.J.I.-G., J.M.T.-S., and J.S.-M.; methodology, F.A.C.-I., F.J.I.-G., J.M.T.-S., and J.S.-M.; software, J.M.T.-S. and J.S.-M.; validation, F.A.C.-I. and F.J.I.G.; formal analysis, F.A.C.-I. and F.J.I.-G.; investigation, J.M.T.-S. and J.S.-M.; resources, F.A.C.-I.; data curation, F.J.I.-G.; writing—original draft preparation, J.S.-M.; writing—review and editing, J.M.T.-S.; visualization, J.M.T.-S.; supervision, F.A.C.-I.; project administration, J.S.-M.; funding acquisition, F.A.C.-I. All authors have read and agreed to the published version of the manuscript.

Funding: This research received no external funding.

Institutional Review Board Statement: Not applicable.

Informed Consent Statement: Not applicable.

Data Availability Statement: Data is contained within the article. 
Acknowledgments: Technical and human support provided by CICT of Universidad de Jaén (UJA, MINECO, Junta de Andalucía, FEDER) is gratefully acknowledged.

Conflicts of Interest: The authors declare no conflict of interest.

\section{References}

1. Muvawala, J.; Sebukeera, H.; Ssebulime, K. Socio-economic impacts of transport infrastructure investment in Uganda: Insight from frontloading expenditure on Uganda's urban roads and highways. Res. Transp. Econ. 2020, 100971. [CrossRef]

2. Plati, C. Sustainability factors in pavement materials, design, and preservation strategies: A literature review. Constr. Build. Mater. 2019, 211, 539-555. [CrossRef]

3. Shi, X.; Mukhopadhyay, A.; Zollinger, D.; Grasley, Z. Economic input-output life cycle assessment of concrete pavement containing recycled concrete aggregate. J. Clean. Prod. 2019, 225, 414-425. [CrossRef]

4. Arabani, M.; Azarhoosh, A. The effect of recycled concrete aggregate and steel slag on the dynamic properties of asphalt mixtures. Constr. Build. Mater. 2012, 35, 1-7. [CrossRef]

5. Morseletto, P. Targets for a circular economy. Resour. Conserv. Recycl. 2020, 153, 104553. [CrossRef]

6. Simone, A.; Vignali, V.; Lantieri, C. A New "Frugal" Approach to Road Maintenance: 100\% Recycling of a Deteriorated Flexible Pavement. In Proceedings of the 7th International Conference on Maintenance and Rehabilitation of Pavements and Technological Control, MAIREPAV 2012, Auckland, New Zealand, 28-30 August 2012.

7. Kalyan, G.; Ramesh, A.; Ramayya, V.V. Performance evaluation of warm mix asphalt mixture with partial inclusion of reclaimed asphalt pavement materials. Mater. Today Proc. 2020. [CrossRef]

8. Menaria, Y.; Sankhla, R. Use of Waste Plastic in Flexible Pavements-Green Roads. Open J. Civ. Eng. 2015, 5, 299-311. [CrossRef]

9. Jain, S.; Singh, B. Cold mix asphalt: An overview. J. Clean. Prod. 2021, 280, 124378. [CrossRef]

10. Turk, J.; Pranjić, A.M.; Mladenovič, A.; Cotič, Z.; Jurjavčič, P. Environmental comparison of two alternative road pavement rehabilitation techniques: Cold-in-place-recycling versus traditional reconstruction. J. Clean. Prod. 2016, 121, 45-55. [CrossRef]

11. Al-Busaltan, S.; Al Nageim, H.; Atherton, W.; Sharples, G. Green Bituminous Asphalt relevant for highway and airfield pavement. Constr. Build. Mater. 2012, 31, 243-250. [CrossRef]

12. Demirbas, A. Waste management, waste resource facilities and waste conversion processes. Energy Convers. Manag. 2011, 52, 1280-1287. [CrossRef]

13. Anthonissen, J.; Van den Bergh, W.; Braet, J. Review and environmental impact assessment of green technologies for base courses in bituminous pavements. Environ. Impact Assess. Rev. 2016, 60, 139-147. [CrossRef]

14. Jin, R.; Li, B.; Zhou, T.; Wanatowski, D.; Piroozfar, P. An empirical study of perceptions towards construction and demolition waste recycling and reuse in China. Resour. Conserv. Recycl. 2017, 126, 86-98. [CrossRef]

15. Mistry, R.; Roy, T.K. Performance evaluation of bituminous mix and mastic containing rice husk ash and fly ash as filler. Constr. Build. Mater. 2020, 121187. [CrossRef]

16. Lokesh, Y. Study on the Effect of Stone, Dust, Ceramic Dust and Brick Dust as Fillers on the Strength, Physical and Durability Properties of Bituminous Concrete (BC-II) Mix. Int. J. Appl. Eng. Res. 2018, 13, 203-208.

17. Sangiorgi, C.; Lantieri, C.; Dondi, G. Construction and demolition waste recycling: An application for road construction. Int. J. Pavement Eng. 2015, 16, 530-537. [CrossRef]

18. Zhu, J.; Ma, T.; Fan, J.; Fang, Z.; Chen, T.; Zhou, Y. Experimental study of high modulus asphalt mixture containing reclaimed asphalt pavement. J. Clean. Prod. 2020, 263, 121447. [CrossRef]

19. Zhou, Z.; Gu, X.; Jiang, J.; Ni, F.; Jiang, Y. Fatigue cracking performance evaluation of laboratory-produced polymer modified asphalt mixture containing reclaimed asphalt pavement material. Constr. Build. Mater. 2019, 216, 379-389. [CrossRef]

20. Zakaria, N.M.; Hassan, M.K.; Ibrahim, A.N.H.; Rosyidi, S.A.P.; Yusoff, N.I.M.; Mohamed, A.A.; Hassan, N. The Use of Mixed Waste Recycled Plastic and Glass as an Aggregate Replacement in Asphalt Mixtures. J. Teknol. 2017, 80, 79-88. [CrossRef]

21. Wu, S.; Montalvo, L. Repurposing waste plastics into cleaner asphalt pavement materials: A critical literature review. J. Clean. Prod. 2021, 280, 124355. [CrossRef]

22. Gala, A.; Guerrero, M.; Serra, J.M. Characterization of post-consumer plastic film waste from mixed MSW in Spain: A key point for the successful implementation of sustainable plastic waste management strategies. Waste Manag. 2020, 111, 22-33. [CrossRef] [PubMed]

23. Escorias de Acería de Horno de Arco Eléctrico. CEDEX. Available online: http://www.cedexmateriales.es/catalogo-de-residuos/ 25/escorias-de-aceria-de-horno-de-arco-electrico/ (accessed on 31 October 2020).

24. Sorlini, S.; Sanzeni, A.; Rondi, L. Reuse of steel slag in bituminous paving mixtures. J. Hazard. Mater. 2012, 84-91. [CrossRef] [PubMed]

25. Pasetto, M.; Baliello, A.; Giacomello, G.; Pasquini, E. Sustainable solutions for road pavements: A multi-scale characterization of warm mix asphalts containing steel slags. J. Clean. Prod. 2017, 166, 835-843. [CrossRef]

26. Motevalizadeh, S.M.; Sedghi, R.; Rooholamini, H. Fracture properties of asphalt mixtures containing electric arc furnace slag at low and intermediate temperatures. Constr. Build. Mater. 2020, 240, 117965. [CrossRef]

27. Zhang, N.; Wu, L.; Liu, X.; Zhang, Y. Structural characteristics and cementitious behavior of basic oxygen furnace slag mud and electric arc furnace slag. Constr. Build. Mater. 2019, 219, 11-18. [CrossRef] 
28. Keymanesh, M.R.; Ziari, H.; Zalnezhad, H.; Zalnezhad, M. Mix design and performance evaluation of microsurfacing con-taining electric arc furnace (EAF) steel slag filler. Constr. Build. Mater. 2020, 121336. [CrossRef]

29. Sideris, K.K.; Tassos, C.; Chatzopoulos, A.; Manita, P. Mechanical characteristics and durability of self compacting concretes produced with ladle furnace slag. Constr. Build. Mater. 2018, 170, 660-667. [CrossRef]

30. Herrero, T.; Vegas, I.J.; Santamaría, A.; San-José, J.T.; Skaf, M. Effect of high-alumina ladle furnace slag as cement substitution in masonry mortars. Constr. Build. Mater. 2016, 123, 404-413. [CrossRef]

31. Sáez-De-Guinoa Vilaplana, A.; Ferreira, V.J.; López-Sabirón, A.M.; Aranda-Usón, A.; Lausín-González, C.; Berganza-Conde, C.; Ferreira, G. Utilization of Ladle Furnace slag from a steelwork for laboratory scale production of Portland cement. Constr. Build. Mater. 2015, 94, 837-843. [CrossRef]

32. Manso, J.M.; Ortega-López, V.; Polanco, J.A.; Setién, J. The use of ladle furnace slag in soil stabilization. Constr. Build. Mater. 2013, 40, 126-134. [CrossRef]

33. Adolfsson, D.; Engström, F.; Robinson, R.; Björkman, B. Cementitious Phases in Ladle Slag. Steel Res. Int. 2010, 82, 398-403. [CrossRef]

34. Shi, C. Characteristics and cementitious properties of ladle slag fines from steel production. Cem. Concr. Res. 2002, 32, 459-462. [CrossRef] 